\title{
Don't Interrupt Me! An Examination of the Relationship Between Intrusions at Work and Employee Strain
}

\author{
Bing C. Lin \\ Portland State University \\ Jason M. Kain \\ Fairfax County Public School System, Fairfax, Virginia \\ Charlotte Fritz \\ Portland State University
}

\begin{abstract}
Interruptions by others, or intrusions, are a common phenomenon in today's workplaces. Intrusions can be disruptive for employees because they displace time required to complete job tasks (thereby increasing perceptions of workload). However, from a resources perspective, intrusions are associated with strain incrementally beyond that of displaced time through the depletion of self-regulatory and cognitive resources. That is, intrusions explain incremental variability in strain (i.e., emotional exhaustion, physical complaints, and anxiety). In a sample of 252 U.S. employees recruited through StudyResponse, we found that workload explained $12 \%$ of variability in exhaustion, $11 \%$ of variability in physical complaints, and $7 \%$ of variability in anxiety. However, intrusions accounted for significant incremental validity beyond that of workload in exhaustion (9\%), physical complaints (4\%), and anxiety (3\%). These results suggest intrusions are associated with strain, uniquely, beyond that of workload.
\end{abstract}

Keywords: interruptions, intrusions, strain

This article was published Online First January 28, 2013.

Bing C. Lin, Department of Psychology, Portland State University; Jason M. Kain, Fairfax County Public School System, Fairfax, Virginia; Charlotte Fritz, Department of Psychology, Portland State University.

Correspondence concerning this article should be addressed to Bing C. Lin, Department of Psychology, Portland State University, Portland, OR 97201-0751. E-mail: bclin@pdx.edu 
Being interrupted by e-mail, phone calls, and colleague inquiries is a common phenomenon in today's workplaces (Berger \& Merritt, 1998; Grove, 1983; Mintzberg, 1990). Interruptions are generally defined as temporary halts in task-related behavior due to the onset of a demand or secondary task (Eyrolle \& Cellier, 2000). As organizations seek to maximize performance, it becomes essential to share information quickly and constantly. This information sharing has been intensified due to technological advances, such as the introduction of e-mail and cellular phonesall of which can provide sources for instantaneous information sharing, but can also function as new media through which coworkers may halt each other's work flow and effectiveness (e.g., Cutrell, Czerwinski, \& Horvitz, 2001). In a technical report by Basex, an economy research firm, it was reported that interruptions at work consume an average of 2.1 hours per day, and that the subsequent lost productivity costs the U.S. economy $\$ 588$ billion dollars per year based on lost time (Spira \& Feintuch, 2005). According to Dismukes, Young, and Sumwalt (1998), nearly half of all aviation accidents are a result of lapses of concentration due to interruptions. Research further indicates that emergency room physicians experienced roughly 10 interruptions per hour, possibly impairing the quality of patient care (Chisholm, Collison, Nelson, \& Cordell, 2000). Thus, examining interruptions and their impact on employees and organizations is highly relevant in today's working world (Wallis \& Steptoe, 2006).

Researchers from ergonomics, human-computer interface, and cognitive psychology have largely driven the research on interruptions, in spite of its growing relevance to organizations. However, Jett and George (2003) recently developed a taxonomy of interruptions suggesting interruptions consist of four different manifestations: distractions, breaks, discrepancies, and intrusions. Although distractions (see Trafton \& Monk, 2008), breaks (see Tucker, Folkard, \& Macdonald, 2003), and discrepancies (see Sweeny, Melnyk, Miller, \& Shepperd, 2010 for a review on information avoidance or the avoidance of discrepancies) have received research attention, intrusions at work, or unexpected interruptions caused by others, have received little. The need to study intrusions is exacerbated given the rapid introduction of new technologies creating new media through which employees can intrude upon each other (Wallis \& Steptoe, 2006). Given the prevalence of intrusions in the modern workplace, it is imperative to understand the relationships between intrusions and employee strain. Although the effects of interruptions on time have been documented (e.g., Spira \& Feintuch, 2005), intrusions have the potential to further impact the U.S. economy through the generation of employee strain reactions. Strain reactions are also known to have various direct and indirect costs for organizations through outcomes such as employee withdrawal (Quick, Quick, Nelson, \& Hurrell, 1997). Thus, the present 
study will examine the relationship between intrusions and strain, beyond the effects of displaced time.

\section{INTRUSIONS AT WORK}

Jett and George (2003) suggest that interruptions can take four forms: distractions, breaks, discrepancies, and intrusions. Distractions were defined as psychological reactions to stimuli that disrupt task continuity, breaks were defined as recesses from work, and discrepancies were defined as inconsistencies between one's expectations and observations of their external world. Intrusions at work, on the other hand, were defined as unexpected temporary halts in job task-related behavior due to the onset of a secondary task or demand brought upon by another individual. In addition to face-to-face interactions (e.g., knocking on a coworker's office door), intrusions can also include interactions through other media (e.g., e-mail, phone calls, and instant messages). For example, in a study of office workers, Zijlstra, Roe, Leonora, and Krediet (1999) had participants perform various text-editing tasks, and confederates interrupted these tasks through two methods. Confederates would intrude on participants by either calling to request a phone number, or call to request participants edit a second document. Zijlstra and colleagues found that employees performed core tasks (i.e., text-editing) faster when exposed to more intrusions; however, this was coupled with declines in well-being. Though not explicitly stated within the study, this study manipulated the number of discrete intrusions experienced by participants. However, Zijlstra et al.'s study only spanned 8 hours spaced out over 3 days, and participants experienced up to three intrusions per day. Considering that the average full-time employee works 7.5 hours per day (United States Department of Labor, 2011) and certain occupations, such as emergency physicians, can experience between 10 and 31 interruptions every 3 hours (Chisholm et al., 2000), it is unclear whether the relationships found by Zijlstra et al. can be generalized to the average worker. First, given the short nature of the study, it is conceivable that demand characteristics (e.g., Hawthorne Effects) may have spurred the participants to devote more effort to primary task completion than is sustainable over a longer period of time. That is, participants may have felt compelled to compensate for intrusions by working harder and faster due to their knowledge of being in an experiment. However, over a longer period of time, it is unclear whether employees can sustain this compensatory effort. Second, considering the discrepancy in intrusion frequency between Zijlstra et al.'s study and the interruption frequencies found in naturalistic observation studies (e.g., Chisholm et al., 2000), Zijlstra et al.'s study may not have captured the actual frequency with 
which employees are typically intruded. Specifically, participants in the Zijlstra et al. study were intruded upon at a maximum rate of .38 per hour, although Chisholm, Collison, Nelson, and Cordeli (2000) found that employees in the medical industry were interrupted up to 10.33 times per hour. This discrepancy suggests field research may be in order to capture the actual frequency with which intrusions occur in the field.

Of the few primary studies on intrusions that have been published (it should be noted that the term intrusion has never been explicitly used) research on intrusions has focused measurement at the event level (e.g., Zijlstra, Roe, Leonora, \& Krediet, 1999). That is, previous studies have either focused on the active manipulation of intrusions or the measurement of actual frequency, favoring an examination of objective events. However, past literature in health psychology has departed from a focus on event-based measurement (Holmes \& Rahe, 1967) of stressors to an appraisal-based measurement of stressors (Lazarus \& Folkman, 1984). That is, measurement of stressors (i.e., intrusions in the present study) has departed from focusing on the objective events that may induce a strain reaction to an individuals' appraisal that these events occur chronically over time (favoring survey methodology; e.g., Spector \& Jex, 1998). To date, no studies have examined intrusions as a potential stressor using survey methodology, in spite of intrusions becoming more prevalent in the modern workplace and the accepted departure from objective measures of stressors.

\section{RESOURCE-BASED FRAMEWORK}

Past literature has examined job characteristics from a resource-based framework (e.g., Bakker \& Demerouti, 2007; Schaufeli \& Bakker, 2004). In this vein, the link between intrusions at work and strain can also be understood through a resource-based framework. Resources are broadly defined as "objects, personal characteristics, conditions, or energies that are valued by the individual or that serve as a means for attainment of these objects, personal characteristics, conditions, or energies" (Hobfoll, 1989, p. 516). The Conservation of Resources Theory (COR; Hobfoll, 1989) suggests that strain reactions develop when resources are threatened or consumed. Given past research has never examined intrusions from a resource-based framework, we assume three resources are of particular importance for understanding the relationship between intrusions and employee well-being: Time, selfregulatory resources, and cognitive resources. The relationship between intrusions, time, and well-being has been documented in the popular media (e.g., Joyce, 2005). For example, Washington Post writer Joyce (2005, p. 1) argues that the secondary tasks created by intrusions result in having "way 
too much going on for the amount of time we have to do it." Time is considered a valued resource for employees and is essential for obtaining additional resources. For example, employees invest time in performance episodes to obtain other valued resources such as money (through wages), or self-worth (through successful completion of their tasks). In a BigThink interview with Jason Fried (cofounder of 37 signals; 2010, 3:09), Fried states:

It's all about interruptions. And people go to work today, and then they end up doing most of their real work after work, or on the weekends. So, people are working longer hours, people are tired-I'm working 50-60 hours this week. It's not that there's 50 or 60 hours' worth of work to do, it's because you don't work at work anymore. You go to work to get interrupted.

It seems commonly accepted that intrusions consume time, and depletion of this resource is likely to cause considerable distress (Hobfoll, 1989). However, beyond the resource of time we argue that intrusions consume additional resources (i.e., self-regulatory and cognitive), and intrusions have unique associations with well-being beyond that of their relationship with time.

\section{Self-Regulatory Resources}

Continuous engagement in a primary work task creates a behavioral momentum (e.g., work flow, absorption; Csikszentmihalyi, 1992; Schaufeli \& Bakker, 2004), and continuing this momentum is pleasurable. In the context of intrusions, intrusions not only halt immediate goal-directed behavior, but discontinue pleasurable behavioral momentum-two behavioral processes likely to trigger negative emotional response (e.g., frustration; Berkowitz, 1989). Thus, attending to intrusions likely requires selfregulatory resources, or our capacity to perform volitional behaviors that do not result in immediate pleasure (Ego Depletion Model; Baumeister, Bratslavsky, Muraven, \& Tice, 1998). Attending to intrusions requires a conscious decision to engage in an interaction that evokes negative emotions (e.g., frustration). This conscious decision and the effort used to sustain effort on addressing intrusions consume self-regulatory resources. Furthermore, intrusions are inherently a dyadic process involving a target employee and an intruder. Universal workplace display rules (i.e., expectations for emotional expression; Ekman \& Friesen, 1975; Hochschild, 1983) typically discourage the display of frustrated affect toward their fellow employees, forcing employees to fake, suppress, and modify their affective expressions (Ashforth \& Humphrey, 1993; Grandey, 2000) when experiencing intrusions. This emotional suppression is also thought to consume self-regulatory resources as the maintenance of emotional displays consistent with display rules, particularly 
when one experiences emotions inconsistent with display rules, requires the exercise of volition (Grandey, 2003).

\section{Cognitive Resources}

The Cognitive Fatigue Model (CFM; Cohen, 1980), based on Glass and Singer's (1972) adaptive-cost hypothesis, suggests that uncontrollable and unpredictable stressors require high levels of cognitive adaptation because individuals must evaluate the threat of the stressor, and formulate an appropriate response to the stressor in a short period of time (Cohen, 1978). Prolonged exposure to uncontrollable, unpredictable stressors result in information overload and elevated levels of cognitive fatigue. Intrusions are unpredictable and uncontrollable because they are inherently unexpected, and are within the control of the intruder rather than the target. Based on the CFM, intrusions are assumed to place heavy demands on cognitive resources as they require a threat appraisal (e.g., estimation of time displaced), in addition to the formulation of appropriate coping strategies (e.g., behavioral strategies for placating the intruder). Kirmeyer (1988) extends the CFM framework by stating that incomplete primary tasks may serve as distractions while attempting to cope with a secondary task. These incomplete primary tasks further place demands on cognitive resources, as individuals must simultaneously appraise threat and formulate coping strategies for the secondary task, all while "tuning out" their incomplete primary task.

\section{INTRUSIONS AND STRAIN REACTIONS}

Occupational Health Psychology has focused on the effects of job demands on strain reactions. Job demands are "physical, psychological, social, or organizational aspects of the job that require sustained physical and/or psychological (i.e., cognitive or emotional) effort and are therefore associated with certain physiological and/or psychological costs" (Schaufeli \& Bakker, 2004, p.296). Job demands can be conceptualized as stressors when they consume or threaten valued resources (Hobfoll, 1989). Beyond time, intrusions also consume self-regulatory and cognitive resources. Therefore, intrusion can be considered a stressor, and prolonged exposure to stressors, such as intrusions, are assumed to induce strain reactions (de Lange, Taris, Kompier, Houtman, \& Bongers, 2003), or the degree of physiological, psychological, or behavioral deviation from an individual's normal healthy functioning (Quick et al., 1997). As intrusions are assumed to deplete or threaten valued resources, strains are thought to be manifestations 
of depleted or threatened resources. To capture this broad definition of strain, we operationalized strain as high levels of emotional exhaustion, physical complaints, and anxiety.

\section{Strain Outcomes}

Emotional exhaustion has been defined by burnout researchers as a result of prolonged physical, affective, and cognitive exertion (Demerouti, Bakker, Nachreiner, \& Schaufeli, 2001). Halbesleben and Demerouti (2005) describe emotional exhaustion as a work-related strain outcome, reflecting a deficit in emotional and physical resources. At its most extreme form, strain reactions can manifest physically. That is, experiencing severe chronic or acute psychological stressors are thought to produce physical manifestations through physical distress (Spector \& Jex, 1998) through the excitation of the autonomic nervous system (Cohen, Tirell, \& Smith, 1991). Physical manifestations of strain, such as headaches or migraines, are thought to be a symptom of long-term resource loss, or severe resource depletion. Anxiety refers to feeling nervous and panicked (Zung, 1971), and past research has identified it as an affective indicator of strain (Caplan \& Jones, 1975).

In the present study, intrusions are assumed to consume three types of resources: Time, self-regulatory, and cognitive resources. According to Hobfoll (1989), prolonged depletion of resources can result in increased strain reactions. Specifically, if we assume that intrusions consume resources, frequent intrusions should result in increased emotional exhaustion, a variable reflective of resource deficit (Halbesleben \& Demerouti, 2005). Physical complaints are assumed to represent an extreme form of resource deficit whereby individuals either experience a severe acute or chronic resource loss. Given that the present study is concerned with the measurement of chronically experiencing frequent intrusions, these should result in chronic selfregulatory and cognitive resource loss. This chronic resource loss should be accompanied by greater physical complaints. Finally, given that intrusions are associated with resource loss, manifesting in increased strain reactions, we hypothesize that intrusions are associated with greater anxiety.

Hypothesis 1: Intrusions are associated with increased strain reactions.

Hypothesis 1a: Intrusions are associated with increased emotional exhaustion.

Hypothesis 1b: Intrusions are associated with increased physical complaints. 
Hypothesis 1c: Intrusions are associated with increased anxiety.

\section{INTRUSIONS, QUANTITATIVE WORKLOAD, AND STRAIN}

Although intrusions may be related to strain strictly due to the consumption of time (Hobfoll, 1989), we argue that intrusions also consume selfregulatory and cognitive resources. That is, we argue that intrusions explain unique variability within strain reactions beyond that of reduced time. Given that intrusions consume time, and seldom advance the employee on their own task progress, intrusions result in having a greater amount of work to complete within a shorter time frame. Thus, the reduction in time as a resource is operationalized in the present study as quantitative workload (heretofore referred to as workload; Spector \& Jex, 1998). Workload is the extent to which one must work at a rapid pace, or work very hard to complete a high volume of work. When time is depleted during intrusions, employees have less time to complete work tasks requiring them to work harder and faster (Zijlstra et al., 1999). Thus, workload is conceptualized as a psychological appraisal to a deficit in time. However, beyond the decreased time allotted to complete work related tasks, we argue that intrusions also consume cognitive and self-regulatory resources. Thus, we hypothesized that intrusions explain incremental variability in strain reactions beyond that of workload.

Hypothesis 2: Intrusions explain incremental variability in strain reactions beyond that of workload.

Hypothesis 2a: Intrusions explain incremental variability in emotional exhaustion beyond that of workload.

Hypothesis 2b: Intrusions explain incremental variability in physical complaints beyond that of workload.

Hypothesis 2c: Intrusions explain incremental variability in anxiety beyond that of workload.

\section{METHOD}

\section{Participants and Procedure}

To collect data for the present study, we used the services of StudyResponse. The StudyResponse project facilitates survey research by distributing 
e-mail participation requests to a heterogeneous sample of adult research participants for a nominal fee. To obtain a sample size of above 200 participants, StudyResponse (2011) recommended they solicit participation from 375 StudyResponse members. Our parameters for solicitation were that participants had full-time jobs, were over 18 years of age, and United State residents. Of the 375 contacted StudyResponse members, 252 employees completed surveys, yielding a response rate of $67.2 \%$. Participants received a $\$ 10$ gift certificate for participating in the study.

As of 2012, 50,538 total workers have participated in StudyResponse sponsored projects (StudyResponse, 2012). The average StudyResponse participant is 34.2 years old $(S D=11.5)$. Sixty-six percent of participants are female, and, on average, have worked 14.5 years $(S D=10.4)$. In comparison, our study sample was an average 42.2 years of age $(S D=10.9)$, and average tenure with their current organization was 8.04 years $(S D=8.9)$. Finally, $47 \%$ of our participants were female. The sample was heterogeneous, in terms of occupations, jobs, and industries, including technical managers, grocery clerks, and ambulance medics.

\section{Measures}

\section{Intrusions}

A 4-item measure assessing intrusions was developed for the purposes of this study. Participants were asked to consider the interruptions they experienced in the past month in their responses. Items for intrusions include: "I am frequently interrupted by others," "I am able to work long periods of time without people interrupting me, "People frequently disturb me while I am trying to do something assigned to me," and "Being interrupted while I am working is a frequent occurrence." Participants were asked to indicate their agreement with these statements using a 5-point Likert scale $(1=$ Strongly Disagree to $5=$ Strongly Agree). To justify aggregating this measure of intrusions, we conducted a principal components analysis, and the first factor extracted accounted for $69.97 \%$ of variance. The measure also demonstrated adequate internal consistency (Cronbach's alpha of .86). Thus, we felt justified in aggregating the measure.

\section{Strain Reactions}

Emotional exhaustion was measured using the 8-item subscale of the Oldenburg Burnout Inventory (OLBI; Halbesleben \& Demerouti, 2005). A 
sample item was: "There are days I feel already tired before I go to work." Participants were instructed to think about the past month and respond using a 4-point Likert-type scale $(1=$ Strongly Disagree to $4=$ Strongly Agree $)$. Physical complaints were measured using Spector and Jex's 18 item Physical Symptoms Inventory (PSI, 1998). Participants were instructed to think about the past month and asked whether they had experienced the symptoms, and to respond using a 3-point response scale with anchors $1=N o ; 2=Y e s$, but I didn't see a doctor; $3=$ Yes, and I saw a doctor. Anxiety was measured using 11 items from the Self-Rating Anxiety Scale by Zung (1971). The scale included a sample item: "I feel more nervous and anxious than usual." Participants were instructed to think about the past month and asked to respond to how intensely they experienced each item using a 4-point scale ( $1=$ Very slightly/not at all to $4=$ Extremely). Emotional exhaustion, physical complaints, and anxiety all demonstrated adequate internal consistency (Cronbach's alphas of .84, .85, and .89, respectively).

\section{Control Variables}

We used four control variables in the present study selected for conceptual and methodological reasons. First, given that Hypothesis 2 explicitly examines the effects of intrusions on strain beyond that of workload, we measure workload using Spector and Jex's (1998) 5-item Quantitative Workload Inventory (QWI). QWI refers to the volume or pace at which one must work, such that when employees must work quickly or have a great deal to complete, they report higher levels of QWI. QWI was used to operationalize decreased time because work is inherently time-bound. When one experiences too much work to do with too little time to complete it (i.e., decreased time) they likely must work faster and harder to compensate (Zijlstra et al., 1999). Thus, QWI can be considered a behavioral manifestation of time deficit. Sample items for this measure include "How often did your job require you to work very fast?" and participants were instructed to think about the past month and asked to respond using a 5-point Likert scale $(1=$ Never to $5=$ Quite Often). We also chose to control for managerial status (1 = Manager; 2 = Non-Manager), and collaboration hours ("How many hours/week do you spend working with others?") because we assumed that these variables could serve as "third variables," or the variables accounting for the relationship between intrusions and strain.

Given the restrictive internal validity concerns of the present design, we also included one final control variable. Lindell and Whitney (2001; Marker Variable Technique) argue that inflated correlations between study variables resulting from common methods can be alleviated by statistically controlling 
for a theoretically unrelated construct that was measured using the same method. This procedure is predicated on the assumption that covariance between two variables that are theoretically unrelated is due to common methods. Thus, controlling for a theoretically unrelated variable statistically partials out variance due to common methods. We chose Scott and Bruce's (1994) 6-item measure of creativity as our common methods variable. A sample item from this measure includes: "I generate creative ideas." Participants were instructed to think about the past month and asked to respond based on a 5-point Likert-type scale $(1=$ Not at All to $5=$ Always $)$. Creativity demonstrated adequate internal consistency (Cronbach's alpha of $.90)$.

\section{RESULTS}

Means, standard deviations, Cronbach's alphas, and correlations are displayed in Table 1.

We used hierarchical regression models to test all of our hypotheses, using the first step of the regression models to control for creativity, managerial status, and collaboration hours, and the second and third steps to test each hypothesis. Specifically, to Test Hypothesis 1 (intrusions are associated with increased strain reactions), three hierarchical regression models were specified with control variables (creativity, managerial status, and collaboration hours) were entered in the first step of the analysis, and intrusions were entered into the second step of the regression model predicting emotional exhaustion, physical complaints, and anxiety. Results suggest that intrusions were significantly associated with each strain variable. Specifically, intrusions accounted for a significant proportion of variance in emotional exhaustion $\left(\beta=.40, p<.01, \Delta R^{2}=.15\right)$, physical complaints $(\beta=.31, p<.01$,

Table 1. Means, Standard Deviations, Cronbach's Alphas, and Correlations

\begin{tabular}{lrrrrrrrrrr}
\hline \multicolumn{1}{c}{ Variable } & $M$ & $S D$ & 1 & 2 & 3 & 4 & 5 & 6 & 7 & 8 \\
\hline 1. Managerial status & $45 \%^{\mathrm{b}}$ & - & - & & & & & & \\
2. Collaboration hours & 22.89 & 14.84 & $-.24^{* *}$ & - & & & & & \\
3. Creativity & 3.31 & .89 & $-.41^{* * *}$ & $.14^{*}$ & $\mathbf{. 9 0}$ & & & & \\
4. Intrusions & 3.37 & .89 & -.03 & $.21^{* *}$ & -.08 & $\mathbf{. 8 6}$ & & & \\
5. Workload & 3.30 & .74 & -.09 & $.15^{*}$ & $.14^{*}$ & $.37^{*}$ & $\mathbf{. 8 3}$ & & & \\
6. Emotional exhaustion & 2.85 & .69 & .10 & .06 & $.28^{* *}$ & $.41^{* *}$ & $.29^{* *}$ & $\mathbf{. 8 4}$ & & \\
7. Physical complaints & 1.31 & .28 & $-.14^{*}$ & .07 & -.04 & $.27^{* *}$ & $.26^{* *}$ & $.50^{* *}$ & $\mathbf{. 8 5}$ & \\
8. Anxiety & 1.82 & .60 & .03 & .10 & $-.18^{* *}$ & $.28^{* *}$ & $.27^{* *}$ & $.67^{* *}$ & $.56^{* *}$ & $\mathbf{. 8 9}$ \\
\hline
\end{tabular}

Note. Cronbach's alphas are reported in the diagonals for each respective scale. Creativity, Workload, Intrusions were rated on a 1-5 scale. Emotional exhaustion and Anxiety were rated on 1-4 scale. Physical complaints were rated on a 1-3 scale.

${ }^{\mathrm{a}} 55 \%$ of participants were male. ${ }^{\mathrm{b}} 45 \%$ of participants were currently supervising employees.

${ }^{*} p<.05 . \quad{ }^{* *} p<.01$. 
$\left.\Delta R^{2}=.09\right)$, and anxiety $\left(\beta=.25, p<.01, \Delta R^{2}=.06\right)$, providing robust support for Hypothesis 1 (see Table 2).

To Test Hypothesis 2 (intrusions explain incremental validity in strain reactions beyond that of workload), three hierarchical regression models were specified with control variables (i.e., managerial status, collaboration hours, and creativity) entered into the first step, our conceptual control variable, workload, entered into the second step, and intrusions entered into the third step. Results suggest workload was significantly associated with each strain variable, and intrusions were significantly associated with each strain variable beyond that of workload. Specifically, workload accounted for a significant proportion of variance in emotional exhaustion $(\beta=.35, p<$ $\left..01, \Delta R^{2}=.12\right)$, and intrusions explained incremental variability in emotional exhaustion beyond that of workload $\left(\beta=.32, p<.01, \Delta R^{2}=.09\right)$. Workload accounted for a significant proportion of variance in physical complaints $\left(\beta=.33, p<.01, \Delta R^{2}=.11\right)$, and intrusions explained incremental variability in physical complaints beyond that of workload $(\beta=$ $\left..22, p<.01, \Delta R^{2}=.04\right)$. Finally, results suggest that workload accounted for a significant proportion of variance in anxiety $\left(\beta=.28, p<.01, \Delta R^{2}=.07\right)$, and intrusions explained incremental variability in anxiety beyond that of workload $\left(\beta=.17, p<.01, \Delta R^{2}=.03\right)$. These results provide robust support for Hypothesis 2 (see Table 3).

\section{DISCUSSION}

\section{Summary of Results}

Results from the current study suggest that intrusions are associated with a variety of strain variables that represent losses in multiple forms of resources (e.g., physical, affective, cognitive). Furthermore, our results sug-

Table 2. Hierarchical Regression of Strain on Intrusions

\begin{tabular}{|c|c|c|c|c|c|c|}
\hline \multirow[b]{2}{*}{ Variable } & \multicolumn{2}{|c|}{ Exhaustion } & \multicolumn{2}{|c|}{ Phys. complaints } & \multicolumn{2}{|c|}{ Anxiety } \\
\hline & $\beta$ & $\Delta R^{2}$ & $\beta$ & $\Delta R^{2}$ & $\beta$ & $\Delta R^{2}$ \\
\hline Step 1 & & .10 & & .04 & & .05 \\
\hline Managerial status & .01 & & $-.18^{* *}$ & & -.02 & \\
\hline Collaboration hours & .11 & & .06 & & .12 & \\
\hline Creativity & $-.32^{* *}$ & & $-.17^{*}$ & & $-.21^{* *}$ & \\
\hline Step 2 & & $.15^{* *}$ & & $.09^{* *}$ & & $.06^{* * *}$ \\
\hline Intrusions & $.40^{* *}$ & & $.31^{* *}$ & & $.25^{* *}$ & \\
\hline
\end{tabular}

Note. "Exhaustion" denotes emotional exhaustion; "Phys. complaints" denotes physical complaints.

${ }^{*} p<.05 .{ }^{* *} p<.01$. 
Table 3. Hierarchical Regression of Strain on Intrusions and Workload

\begin{tabular}{|c|c|c|c|c|c|c|}
\hline \multirow[b]{2}{*}{ Variable } & \multicolumn{2}{|c|}{ Exhaustion } & \multicolumn{2}{|c|}{ Phys. complaints } & \multicolumn{2}{|c|}{ Anxiety } \\
\hline & $\beta$ & $\Delta R^{2}$ & $\beta$ & $\Delta R^{2}$ & $\beta$ & $\Delta R^{2}$ \\
\hline Step 1 & & .10 & & .04 & & .05 \\
\hline Managerial status & .01 & & $-.18^{* *}$ & & -.02 & \\
\hline Collaboration hours & .11 & & .06 & & .12 & \\
\hline Creativity & $-.32^{* *}$ & & $-.17^{*}$ & & $-.21^{* *}$ & \\
\hline Step 2 & & $.12^{* * *}$ & & $.11^{* *}$ & & $.07^{* *}$ \\
\hline Workload & $.35^{\text {*** }}$ & & $.33^{* *}$ & & $.28^{* *}$ & \\
\hline Step 3 & & $.09^{* *}$ & & $.04^{* *}$ & & $.03^{*}$ \\
\hline Intrusions & $.32^{* * *}$ & & $.22^{* * *}$ & & $.17^{* * *}$ & \\
\hline
\end{tabular}

Note. "Exhaustion" denotes emotional exhaustion; "Phys. complaints" denotes physical complaints.

${ }^{*} p<.05 . \quad{ }^{* *} p<.01$.

gest that above and beyond the relationship between time deficits and strain, intrusions also consume other types of resources (i.e., self-regulatory and cognitive), that explain the relationship between intrusions and strain. It is particularly interesting that intrusions were associated with all types of strain variables, including both work-related (i.e., emotional exhaustion), and global forms of strain reactions (i.e., physical complaints and anxiety). These results corroborate some of the work conducted by work - family researchers, most notably in the spillover arena, such that strain may transfer between employees' work and family domain (Williams \& Alliger, 1994).

Additionally, the results from the present study demonstrate that intrusions can be captured at the chronic level using survey methodology. Furthermore, given the strong effect sizes between intrusions and strain reactions, future research attempting to examine intrusions as a stressor should consider using survey methodology to measure individuals' appraisal of intrusions.

\section{Limitations and Future Directions}

The current study is a first step in understanding a phenomenon increasing in relevance in modern work places. However, some questions remain and new ones arise. For example, due to the cross-sectional design of our study, causal inferences between intrusions, workload, and strain are not possible. Thus, future studies attempting to model this causal chain should use more advanced methodology, such as prospective designs and diary studies.

Although the present study introduces the possibility of using survey methodology to study a phenomenon that has largely been examined in experimental settings, future endeavors to use survey methodology to examining intrusions at work should be wary of possible challenges. For example, to better understand the dynamics and outcomes of intrusions at work, it may 
be necessary to differentiate between interruption lag, secondary task, and resumption lag. However, such a differentiation may be difficult to capture using survey methodology, calling for more refined research designs and methodology, such as daily diary designs to capture the immediate processes inherent in the intrusion process. However, it should be noted that in certain instances, requests for completing surveys can also serve as intrusions. Thus, caution should be taken when using more sophisticated designs.

Third, although the present study provides robust support for the positive relationship between intrusions and strain reactions, there may be boundary conditions under which intrusions can be conducive for employee strain and job performance. For example, intrusions may open the potential for social support or break the monotony of a boring or simple task by introducing an extra challenge to task completion (Jett \& George, 2003). Thus, possible moderators may exist that either buffer, or alter, the relationship between intrusions and strain reactions.

Finally, the present study represents the first attempt to incorporate a resource-based model to the study of intrusions. Extending the notion that intrusions consume self-regulatory and cognitive resources, examining the behavioral outcomes of frequent intrusions could present a fruitful future endeavor. For example, past research has shown that employees with selfregulatory resource deficits are likely to exhibit greater workplace deviance (Christian \& Ellis, 2011). Continuing the assumption that intrusions consume self-regulatory resources, chronic exposure to intrusions may also be associated with workplace deviance. Additionally, research has demonstrated that the use of heuristics and biases may be more prevalent when cognitive resources are depleted (e.g., Macrae, Milne, \& Bodenhausen, 1994). If we continue to assume intrusions consume cognitive resources, employees who experience chronic intrusions may be inclined to make poorer decisions at work (e.g., poorer selection decisions, lowered safety outcomes).

\section{Practical Implications}

Although intrusions may be helpful for instantaneous information sharing, our results indicate that these intrusions are associated with lower employee well-being. Thus, intrusions can be conceptualized as a workplace stressor. To promote employee health and wellness, organizations should take steps to reduce the occurrence of stressors, such as intrusions. For example, if an employee is working on a project that requires substantial collaboration, it is not enough to merely decrease their regular workload, or be sensitive to missed deadlines due to their decreased time on task. Managers should do their best to maintain workspaces with fewer intrusions by 
implementing quiet time (i.e., allotting 2-3 hours per day where employees are discouraged from intruding on their coworkers), or reconsidering open floor plans.

Additionally, employees can proactively attempt to reduce intrusions. For example, an intrusion is an inherently dyadic process that involves at least two employees: the target employee and an intruder. In many white collar work settings, employees can view each other's calendars to streamline meeting scheduling, and also to view when employees are available. Simply having individuals, who would otherwise be intruders, instead schedule their unscheduled meeting or visit for later in the day can minimize the unexpectedness and uncontrollability of the intrusion as the target employee is then able to both anticipate the likelihood of a break in workflow, and/or reject or reschedule the meeting for a later date. By scheduling an intrusion, intruders are effectively removing intrusions from the workplace, given that they are no longer unanticipated.

Employees can also take steps to reduce the deleterious effects of intrusions. For example, they can minimize the time between intrusion and primary task resumption by using visual cues. For example, during the onset of an intrusion, an employee working on writing a technical report can highlight the last few words they typed prior to addressing the intrusion. Research has demonstrated that using small visual cues such as this can facilitate the attention transfer back to the primary task once the intrusion has been completed (McDaniel, Einstein, Graham, \& Rall, 2004). This decreases the amount of time intrusions consume.

However, the present study demonstrates that intrusions account for strain reactions beyond the effects of time. Thus, steps should be taken to reduce the self-regulatory and cognitive resource loss characteristic of experiencing frequent intrusions. Training employees to delay addressing intrusions by asking intruders to wait (e.g., "Can you give me 15 minutes?") can provide the first step in minimizing the extent to which intrusions prevent goal-directed behavior (Monk, Boehm-Davis, \& Trafton, 2004). This is particularly the case if intrusions can be delayed until employees complete their primary task. In these instances, intrusions are delayed till "coarse break points." To the extent intrusions no longer prevent immediate goal completion, this tactic can be instrumental in reducing self-regulatory resource consumption.

\section{Contributions}

Most previous research in the realm of intrusions has been conducted experimentally, and this is the first known study to explore intrusions using 
a survey methodology in a field setting. The results from the current study show that intrusions in the workplace can be examined using survey research methods, and results are generally consistent with what one would expect of a stressor. Additionally, our study is the first to relate the phenomenon of intrusions at work to broader social psychological theories, rather than the human-computer interaction, ergonomic, and cognitive psychology theories that are typical of interruptions literature. Finally, this study is one of a few that focuses on interruptions and employee well-being, a burgeoning concern for organizations.

\section{REFERENCES}

Ashforth, B. E., \& Humphrey, R. H. (1993). Emotional labor in service roles: The influence of identity. The Academy of Management Review, 18, 88-115.

Bakker, A. B., \& Demerouti, E. (2007). The jobs demands-resources model: State of the art. Journal of Managerial Psychology, 22, 309-328. doi:10.1108/02683940710733115

Baumeister, R. F., Bratslavsky, E., Muraven, M., \& Tice, D. M. (1998). Ego depletion: Is the active self a limited resource? Journal of Personality and Social Psychology, 74, 12521265. doi:10.1037/0022-3514.74.5.1252

Berger, F., \& Merritt, E. A. (1998). No time left for you. Cornell Hotel and Restaurant Administration Quarterly, 39, 32-40. doi:10.1177/001088049803900508

Berkowitz, L. (1989). Frustration-Aggression Hypothesis: Examination and reformulation. Psychological Bulletin, 106, 59-73. doi:10.1037/0033-2909.106.1.59

BigThink (Interviewer) \&Fried, J. (Interviewee). (2010). Why you can't work at work [Interview transcript]. Retrieved from BigThink Business \& Economics http://bigthink.com/ ideas $/ 18522 /$

Caplan, R. D., \& Jones, K. W. (1975). Effects of work load, role ambiguity, and type A personality on anxiety, depression, and heart rate. Journal of Applied Psychology, 60, $713-719$.

Chisholm, C. D., Collison, E. K., Nelson, D. R., \& Cordell, W. H. (2000). Emergency department workplace interruptions: Are emergency physicians "interrupt-driven" and "multitasking?" Academic Emergency Medicine, 7, 1239-1243. doi:10.1111/j.1553-2712 .2000.tb00469.x

Christian, M. S., \& Ellis, A. P. J. (2011). Examining the effects of sleep deprivation on workplace deviance: A self-regulatory perspective. Academy of Management Journal, 54, 913-934. doi:10.5465/amj.2010.0179

Cohen, S. (1978). Environmental load and the allocation of attention. In A. Baum, J. E. Singer, \& S. Valins (Eds.), Advances in environmental psychology (Vol. 1). Hillsdale, N.J.: Erlbaum.

Cohen, S. (1980). After effects of stress on human performance and social behavior: A review of research and theory. Psychological Bulletin, 88, 82-108. doi:10.1037/0033-2909.88 .1 .82

Cohen, S., Tyrell, D. A. J., \& Smith, A. P. (1991). Psychological stress and susceptibility to the common cold. The New England Journal of Medicine, 325, 606-612. doi:10.1056/ NEJM199108293250903

Csikszentmihalyi, M. (1992). The flow experience and its significance for human psychology. In M. Csikszentmihalyi \& I. Csikszentmihalyi (Eds.), Optimal experience: Psychological studies of flow in consciousness (pp. 15-36). Cambridge, UK: Cambridge University Press. doi:10.1017/CBO9780511621956.002 
Cutrell, E., Czerwinski, M., \& Horvitz, E. (2001). Notification, disruption, and memory: Effects of messaging interruptions on memory and performance. In Interact 2001: IFIP Conference on Human-Computer Interaction (pp. 263-269). Tokyo, Japan: IFIP.

de Lange, A. H., Taris, T. W., Kompier, M. A. J., Houtman, I. L. D., \& Bongers, P. M. (2003). "The very best of the millennium": Longitudinal research and the demand-control(support) model. Journal of Occupational Health Psychology, 8, 282-305.

Demerouti, E., Bakker, A. B., Vardakou, I., \& Kantas, A. (2003). The convergent validity of two burnout instruments: A multitrait-multimethod analysis. European Journal of Psychological Assessment, 19, 12-23. doi:10.1027//1015-5759.19.1.12

Dismukes, R. K., Young, G. E., \& Sumwalt, R. L. (1998). Cockpit interruptions and distractions: Effective management requires a careful balancing act. ASRS Directline, 10, 4-9.

Ekman, P., \& Friesen, W. V. (1975). Unmasking the face. Englewood Cliffs, NJ: Prentice-Hall.

Eyrolle, H., \& Cellier, J.-M. (2000). The effects of interruptions in work activity: Field and laboratory results. Applied Ergonomics, 31, 537-543. doi:10.1016/S00036870(00)00019-3

Glass, D. C., \& Singer, J. E. (1972). Urban Stress: Experiments on Noise and Social Stressors. New York: Academic Press.

Grandey, A. A. (2000). Emotion regulation in the workplace: A new way to conceptualize emotional labor. Journal of Occupational Health Psychology, 5, 95-110. doi:10.1037/ 1076-8998.5.1.95

Grandey, A. A. (2003). When "the show must go on": Surface acting and deep acting as determinants of emotional exhaustion and peer-rated service delivery. Academy of Management Journal, 46, 86-96. doi:10.2307/30040678

Grove, A. S. (1983). High output management. New York, NY: Random House.

Halbesleben, J. B., \& Demerouti, E. (2005). The construct validity of an alternative measure of burnout: Investigating the English translation of the Oldenburg Burnout Inventory. Work \& Stress, 19, 208-220. doi:10.1080/02678370500340728

Hobfoll, S. E. (1989). Conservation of resources: A new attempt at conceptualizing stress. American Psychologist, 44, 513-524. doi:10.1037/0003-066X.44.3.513

Hochschild, A. R. (1983). The managed heart: Commercialization of human feeling. Berkeley, CA: University of California Press.

Holmes, T. H., \& Rahe, R. H. (1967). The social readjustment rating scale. Journal of Psychosomatic Research, 11, 213-218. doi:10.1016/0022-3999(67)90010-4

Jett, Q. R., \& George, J. M. (2003). Work interrupted: A closer look at the role of interruptions in organizational life. The Academy of Management Review, 28, 494-507.

Joyce, A. (2005, January 2). Your interruption strategy: Set priorities and plan on unplanned events. Retrieved from http://www.washingtonpost.com/wp-dyn/articles/A367222004Dec30.html

Kirmeyer, S. L. (1988). Coping with competing demands: Interruption and the Type A pattern. Journal of Applied Psychology, 73, 621-629. doi:10.1037/0021-9010.73.4.621

Lazarus, R. S., \& Folkman, S. (1984). Stress, appraisal, and coping. New York, NY: Springer.

Lindell, M. K., \& Whitney, D. J. (2001). Accounting for common method variance in cross-sectional research designs. Journal of Applied Psychology, 86, 114-121. doi: 10.1037/0021-9010.86.1.114

Macrae, C. N., Milne, A. B., \& Bodenhausen, G. V. (1994). Stereotypes as energy-saving devices: A peek inside the cognitive toolbox. Journal of Personality and Social Psychology, 66, 37-47. doi:10.1037/0022-3514.66.1.37

McDaniel, M. A., Einstein, G. O., Graham, T., \& Rall, E. (2004). Delaying execution time of intentions: Overcoming the costs of interruptions. Applied Cognitive Psychology, 18, 533-547. doi:10.1002/acp.1002

Mintzberg, H. (1990). The manager's job: Folklore and fact. Harvard Business Review, 68, $163-176$.

Monk, C. A., Boehm-Davis, D. A., \& Trafton, J. G. (2004). Recovering from interruptions: Implications for driver distraction research. Human Factors, 46, 650-663. doi:10.1518/ hfes.46.4.650.56816 
Quick, J. C., Quick, J. D., Nelson, D. L., \& Hurrell, J. J., Jr. (1997). Preventative stress management in organizations. Washington DC: American Psychological Association. doi:10.1037/10238-000

Schaufeli, W. B., \& Bakker, A. B. (2004). The demands, job resources, and their relationship with burnout and engagement: A multi-sample study. Journal of Organizational Behavior, 25, 293-315. doi:10.1002/job.248

Scott, S. G., \& Bruce, R. A. (1994). Determinants of innovative behavior: A path model of individual innovation in the workplace. Academy of Management Journal, 37, 580-607. doi:10.2307/256701

Spector, P. E., \& Jex, S. M. (1998). Development of four self-report measures of job stressors and strain: Interpersonal Conflict at Work Scale, Organizational Constraints Scale, Quantitative Workload Inventory, and Physical Symptoms Inventory. Journal of Occupational Health Psychology, 3, 356-367. doi:10.1037/1076-8998.3.4.356

Spira, J. B., \& Feintuch, J. B. (2005). The cost of not paying attention: How interruptions impact knowledge worker productivity. New York, NY: Basex, Inc.

Sweeny, K., Melnyk, D., Miller, W., \& Shepperd, J. A. (2010). Information avoidance: Who, what, when, and why. Review of General Psychology, 14, 340-353. doi:10.1037/ a0021288

The StudyResponse Project. (2011). The StudyResponse Project: An online social science research resource. Retrieved from http://www.studyresponse.net/index.htm

The StudyResponse Project. (2012). Information for Participants: Sample Characteristics. Retrieved from http://www.studyresponse.net/sample.htm

Trafton, J. G., \& Monk, C. A. (2008). Task interruptions. In D. A. Boehm-Davis (Ed.), Reviews of human factors and ergonomics (Vol. 3, pp. 111-126). Santa Monica, CA: Human Factors and Ergonomics Society.

Tucker, P., Folkard, S., \& Macdonald, I. (2003). Rest breaks and accident risk. The Lancet, 361, 680. doi:10.1016/S0140-6736(03)12566-4

United States Department of Labor, Bureau of Labor Statistics. (2011). American time use survey-2010 results (USDL-11-0919). Retrieved from http://www.bls.gov/news.release/ archives/atus_06222011.pdf

Wallis, C., \& Steptoe, S. (2006, January 16). Help! I've lost my focus. Time, 167, 72-79.

Williams, K. J., \& Alliger, G. M. (1994). Role stressors, mood spillover, and perceptions of work-family conflict in employed parents. Academy of Management Journal, 37, 837858. doi:10.2307/256602

Zijlstra, F. R. H., Roe, R. A., Leonora, A. B., \& Krediet, I. (1999). Temporal factors in mental work: Effects of interrupted activities. Journal of Occupational and Organizational Psychology, 72, 163-185. doi:10.1348/096317999166581

Zung, W. W. (1971). A rating instrument for anxiety disorders. Psychosomatics: Journal of Consultation Liaison Psychiatry, 12, 371-379.

Received September 20, 2011

Revision received December 20, 2012

Accepted December 21, 2012 